\title{
HIGHLIGHTS
}

CANCER

\section{Predictors of metabolic outcome after surgery for adrenal incidentaloma}

A combination of parameters related to hypothalamic-pituitary-adrenal axis (HPA) activity may accurately predict the improvement or worsening of metabolic abnormalities after surgical removal of adrenal incidentalomas.

In a retrospective, longitudinal study, Eller-Vainicher et al. assessed the accuracy of presurgical levels of urinary free cortisol (UFC), serum cortisol after an overnight $1 \mathrm{mg}$ dexamethasone suppression test (DST), morning ACTH and midnight serum cortisol (MSC) to predict outcome on features of the metabolic syndrome, including weight, blood pressure and levels of glucose and cholesterol.

HPA axis function was assessed in 55 patients who underwent surgical excision of an adrenal incidentaloma and 53 patients in whom surgery was refused or not indicated, at baseline and at the end of follow-up.

"Treated patients were considered 'improved' or 'not improved' and nontreated patients 'worsened' or 'not worsened' if they experienced alteration of at least two metabolic parameters during follow up," explains senior investigator Iacopo Chiodini.

The presurgical presence of at least two of three parameters, either levels of UFC $>193 \mathrm{nmol} / \mathrm{l}$ over $24 \mathrm{~h}, \mathrm{ACTH}<2.2 \mathrm{pmol} / \mathrm{l}$ or DST $>83 \mathrm{nmol} / \mathrm{l}$, was the most accurate at predicting improvement of two or more metabolic abnormalities after surgery. "This criterion seems to be able to also predict the worsening of at least two metabolic end points in nontreated patients," concludes Chiodini.

Linda Koch

Original article Eller-Vainicher, C. et al. Accuracy of several parameters of hypothalamic-pituitary-adrenal axis activity in predicting before surgery the metabolic effects of the removal of an adrenal incidentaloma. Eur. J. Endocrinol. $163,925-935$ (2010) 